\title{
Seleção de estirpes de rizóbio para Adesmia latifolia (Spreng.) Vogel
}

\author{
Aleksander Westphal Muniz ${ }^{1 *}$ \\ Murilo Dalla Costa ${ }^{2}$ \\ Carmen Lídia Wolff ${ }^{3}$ \\ Walmor Assis Faria de Oliveira ${ }^{4}$ \\ Enilson Saccol de Sá ${ }^{5}$
}

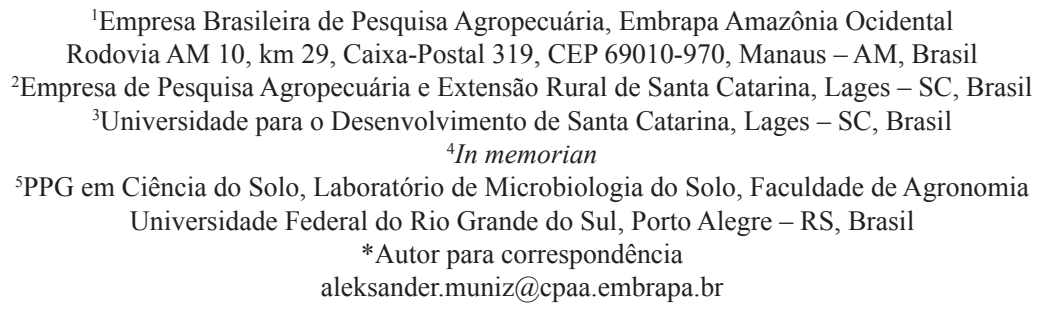

Submetido em 23/09/2011

Aceito para publicação em 06/12/2011

\section{Resumo}

As leguminosas nativas da serra catarinense do gênero Adesmia apresentam um grande potencial para uso como plantas forrageiras como Adesmia latifolia e Adesmia tristis. O objetivo do trabalho foi selecionar estirpes de rizóbio para Adesmia latifolia. O experimento foi conduzido com delineamento completamente casualizado com cinco repetições em casa de vegetação. Os tratamentos foram 11 estirpes de rizóbio da coleção da Epagri e duas testemunhas onde uma com adição de nitrogênio mineral e outra sem nitrogênio.Os resultados obtidos foram analisados estatisticamente com o auxílio do programa Assistat. Para separação de médias foi utilizado o teste de Scott-Knott ao nível de 5\%. Os parâmetros utilizados nessa seleção foram a matéria-seca da parte aérea, nodulação e massa seca de nódulos. Os resultados demonstraram que a estirpe EEL 2399 apresentou o melhor desempenho em todos os parâmetros avaliados com massa seca de $243 \mathrm{mg} / \mathrm{vaso}, 44,33$ nódulos/vaso e massa seca de nódulos de 33,17mg/vaso. Dessa forma a estirpe EEL 2399 pode ser utilizada em testes de seleção de estirpes de rizóbio para Adesmia latifolia em experimentos a campo.

Palavras-chave: Bactérias diazotróficas, Fixação Biológica de Nitrogênio, Nodulação

\section{Abstract}

Selection of rhizobia strains for Adesmia latifolia (Spreng.) Vogel. Legumes of the genus Adesmia, such as Adesmia latifolia and Adesmia tristis, are native to Serra catarinense and show great potential as fodder. The purpose of this study was to select rhizobial strains from Adesmia latifolia. The experiments were conducted in a greenhouse, were completely randomised and were repeated five times. The experiment group consisted of 11 rhizobial strains from the Epagri collection and a control strain, all of which treated with or without mineral 
nitrogen. The results were statistically analysed with the Assistat programme. The Scott-Knott test was used at $5 \%$ to separate the means. The parameters to be evaluated in this selection were the dry matter of shoots, nodulation and the dry weight of nodules. The results showed that strain EEL 2399 had the best performance in all of the evaluated parameters, with values of $243 \mathrm{mg} /$ pot dry matter, 44.33 nodules/pot and a nodule dry weight of $33.17 \mathrm{mg} / \mathrm{jar}$ being observed. Therefore, strain EEL 2399 can be used in tests for identifying rhizobial strains from Adesmia latifolia in field experiments.

Key words: Biological Nitrogen Fixation, Diazotrophic bacteria, Nodulation

O gênero Adesmia é exclusivo da América do Sul e apresenta cerca de 230 espécies. No Brasil, são 17 espécies ao todo. Nos campos nativos da Região Sul, podem ser encontradas as espécies Adesmia arujoi, $A$. latifolia, A. puntacta e A. tristis. Dentre essas, destacamse $A$. arujoi e A. latifolia como ótimas forrageiras (MIOTTO; LEITÃO FILHO, 1993).

A espécie $A$. latifolia apresenta a vantagem de ser estolonífera e teoricamente acumular maior quantidade de forragem do que as espécies herbáceas do gênero (SCHEFFER-BASSO et al., 2005). Além disso, essa espécie produz forragem durante a estação fria e permite dessa forma a alimentação animal durante um período de alimento mais escasso. E ainda apresenta nutrientes mínimos para ruminantes com desempenho similar a espécies exóticas como Lotus corniculatus (SCHEFFER-BASSO et al., 2001).

O gênero Adesmia apresenta uma relação simbiótica rizobactérias diazotróficas do solo (BROUGHTON et al., 2000). Essas bactérias são responsáveis pelo processo de fixação biológica de nitrogênio (FBN), que leva a uma redução na adubação nitrogenada no plantio de pastagens. No entanto, as bactérias diazotróficas autóctones do solo possuem diferentes níveis de eficiência na FBN. Deste modo, em função de seu potencial de utilização faz-se necessário selecionar estirpes com maior capacidade de FBN, a fim de melhorar seu desempenho em cultivos. Assim, o objetivo deste trabalho, portanto consistiu na seleção de estirpes de rizóbio eficazes para simbiose com A. latifolia.

Os isolados de rizóbio, existentes na coleção do laboratório de Biotecnologia da Epagri, foram testados nas plantas hospedeiras de $A$. latifolia cultivadas em vasos com areia e vermiculita estéril $(2: 1 \mathrm{v} / \mathrm{v})$ e solução nutritiva de Hoagland (TAIZ; ZEIGER, 2004).
A composição da solução nutritiva foi modificada nos tratamentos inoculados através da redução de nitrogênio. No início do experimento, cada vaso foi regado com $200 \mathrm{~mL}$ desta solução nutritiva e após quatro semanas foram adicionados mais $100 \mathrm{~mL}$ desta mesma solução por vaso. Para a inoculação das plantas, as bactérias foram desenvolvidas no mesmo meio AML (ÁgarManitol-Levedura) em tubos a uma temperatura de $28^{\circ} \mathrm{C}$ (VINCENT, 1975). Depois do crescimento, cada cultura foi suspensa em água destilada estéril. Desta suspensão foi inoculado um $\mathrm{ml}$ por vaso contendo três plantas germinadas com altura aproximada de $10 \mathrm{~cm}$. Os 11 isolados da coleção foram testados com relação à eficiência na produção de massa seca da parte aérea, número de nódulos e massa seca de nódulos. O experimento foi conduzido com delineamento completamente casualizado com cinco repetições e avaliado após 90 dias de sua implantação. Os resultados obtidos foram analisados estatisticamente com o auxílio do programa Assistat v. 7.5. Para análise de variância e separação de médias, os dados foram transformados através da macro Box-Cox. A eficiência e a eficácia foram determinadas conforme as fórmulas a seguir:

\section{eficiência $=($ MSPA tratamento $\div$ MSPA testemunha $-\mathbf{N})$ $\times 100$ \\ eficácia $=($ MSPA tratamento $\div$ MSPA testemunha $+\mathrm{N}) \times 100$}

Os resultados demonstraram que as estirpes avaliadas podem ser divididas em seis grupos conforme a produção de matéria seca da parte aérea. O grupo I (EEL 2399) apresentou a maior produção de matéria seca com $243 \mathrm{mg} /$ vaso do que os demais grupos. Os demais grupos apresentaram a matéria seca variando entre 81,67 e 178,33mg/vaso (Tabela 1). A massa seca da parte aérea tem-se mostrado como o principal parâmetro 
TABELA 1: Massa seca da parte aérea, número e peso de nódulos de Adesmia latifolia inoculado com estirpes de rizóbio em casa de vegetação e condições hidropônicas. Médias de seis repetições.

\begin{tabular}{lccccc}
\hline \multicolumn{1}{c}{ Estirpe } & $\begin{array}{c}\text { Matéria seca da } \\
\text { parte aérea (mg) }\end{array}$ & $\begin{array}{c}\text { Número de } \\
\text { nódulos }\end{array}$ & $\begin{array}{c}\text { Matéria seca } \\
\text { de nódulos }(\mathbf{m g})\end{array}$ & $\begin{array}{c}\text { Eficiência } \\
(\mathbf{\%})\end{array}$ & $\begin{array}{c}\text { Eficácia } \\
(\mathbf{\%})\end{array}$ \\
\hline EEL 2399 & $243,00 \pm 9,86^{\mathrm{a}}$ & $44,33 \pm 23,50^{\mathrm{a}}$ & $33,17 \pm 16,24^{\mathrm{a}}$ & 407,24 & 231,80 \\
EEL 400 & $178,33 \pm 4,86^{\mathrm{b}}$ & $25,50 \pm 14,86^{\mathrm{b}}$ & $9,02 \pm 6,45^{\mathrm{b}}$ & 298,86 & 170,11 \\
EEL 3100 & $174,50 \pm 4,60^{\mathrm{b}}$ & $32,00 \pm 22,31^{\mathrm{b}}$ & $19,67 \pm 15,28^{\mathrm{b}}$ & 292,44 & 166,46 \\
EEL 100 & $156,33 \pm 1,41^{\mathrm{c}}$ & $20,33 \pm 5,35^{\mathrm{b}}$ & $11,83 \pm 6,49^{\mathrm{b}}$ & 261,99 & 149,13 \\
EEL 1400 & $147,17 \pm 2,28^{\mathrm{c}}$ & $29,00 \pm 25,93^{\mathrm{b}}$ & $17,17 \pm 19,14^{\mathrm{b}}$ & 246,64 & 140,39 \\
EEL 1300 & $139,00 \pm 2,00^{\mathrm{c}}$ & $45,33 \pm 25,16^{\mathrm{a}}$ & $24,83 \pm 14,92^{\mathrm{a}}$ & 232,95 & 132,60 \\
EEL 5692 & $109,83 \pm 2,19^{\mathrm{d}}$ & $21,17 \pm 11,89^{\mathrm{b}}$ & $6,22 \pm 6,20^{\mathrm{b}}$ & 184,06 & 104,77 \\
Test c/ N & $104,83 \pm 2,53^{\mathrm{d}}$ & $0,00 \pm 0,00^{\mathrm{c}}$ & $0,00 \pm 0,00^{\mathrm{b}}$ & 175,68 & 100,00 \\
EEL 2000 & $92,17 \pm 2,45^{\mathrm{d}}$ & $17,00 \pm 9,70^{\mathrm{b}}$ & $10,00 \pm 7,54^{\mathrm{b}}$ & 154,47 & 87,92 \\
EEL 5992 & $81,67 \pm 2,90^{\mathrm{d}}$ & $48,17 \pm 18,78^{\mathrm{a}}$ & $36,50 \pm 12,47^{\mathrm{a}}$ & 136,87 & 77,91 \\
EEL 5892 & $60,17 \pm 4,05^{\mathrm{e}}$ & $37,33 \pm 29,11^{\mathrm{a}}$ & $30,40 \pm 29,98^{\mathrm{a}}$ & 100,84 & 57,40 \\
Test s/ N & $59,67 \pm 2,61^{\mathrm{e}}$ & $0,00 \pm 0,00^{\mathrm{c}}$ & $0,00 \pm 0,00^{\mathrm{b}}$ & 100,00 & 56,92 \\
EEL 300 & $17,00 \pm 3,46^{\mathrm{f}}$ & $41,17 \pm 7,65^{\text {a }}$ & $16,83 \pm 5,23^{\mathrm{b}}$ & 28,49 & 16,22 \\
\hline
\end{tabular}

* Para o cálculo da variância os dados foram transformados pela ferramenta Box-cox. As médias seguidas da mesma letra não diferem significativamente pelo teste de Scott-Knott ao nível de 5\%.

na seleção de estirpes de rizóbio como observado em vários trabalhos com diferentes leguminosas como caupi, ervilha, feijão-de-porco, guandu, lentilha e trevo (BROSE, 1994; FERNANDES et al., 2003; BROSE; MUNIZ, 2008; MUNIZ; BROSE, 2008).Em termos de eficiência e eficácia, ficou evidente a superioridade da estirpe EEL 2399 sobre as demais com 407,24 e 231,80 $\%$, respectivamente.

A nodulação obtida nesse trabalho foi dividida em três grupos (Tabela 1). O grupo I (EEL 2399, EEL 1300, EEL 5992, EEL 5892, EEL 300) que apresentou a maior nodulação que os demais grupos com 41,17 a 45,33 nódulos/vaso. Já o grupo II (EEL 400, EEL 3100, EEL 100, EEL 1400, EEL 5692, EEL 2000) apresentou maior nodulação com 17 a 29 nódulos/vaso do que o grupo III (Testemunha com e sem nitrogênio) que não apresentou nodulação. A massa seca da nodulação obtida foi dividida em dois grupos distintos (Tabela 1). O grupo I (EEL 2399, EEL 1300, EEL 5992, EEL 5892) apresentou maior massa da nodulação com 24,83 a 36,50mg/vaso do que o grupo II (EEL 400, EEL 3100, EEL 100, EEL 1400, EEL 5692, EEL 2000, EEL 300, e Testemunhas com e sem nitrogênio) com 0,00 a 19,63mg/vaso. Os dados de nodulação obtidos divergem de outros trabalhos, onde o número de nódulos não pode ser utilizado como parâmetro de eficiência na seleção de estirpes de rizóbio (BROSE; MUNIZ, 2008; MUNIZ; BROSE, 2008).

Com base nos resultados obtidos pode-se concluir que a estirpe EEL 2399 foi à melhor em todos os parâmetros analisados e pode ser utilizada em testes de seleção para a espécie A. latifolia em experimentos a campo.

\section{Referências}

BROSE, E. Seleção de rizóbio para trevo-branco em solo ácido. Pesquisa Agropecuária Brasileira, Brasília, v. 29, n. 2, p. 281-285, 1994.

BROSE, E.; MUNIZ, A. W. Isolamento e seleção em condições estéreis de estirpes de rizóbio para ervilha. Agropecuária Catarinense, Florianópolis, v. 21, n. 1, p. 92-96, 2008.

BROUGTON, W. J.; JABBOURI, S.; PERRET, X. Keys of symbiotic harmony. Journal of Bacteriology, Washington, v. 182, n. 20 , p. 5641-5652, 2000.

FERNANDES, M. F.; FERNANDES, R. P.; HUNGRIA, M. Seleção de rizóbios nativos para guandu, caupi e feijão-de-porco nos tabuleiros costeiros de Sergipe. Pesquisa Agropecuária Brasileira, Brasília, v. 38, n. 7, p. 835-842, 2003.

MIOTTO, S. T. S.; LEITÃO FILHO, H. F. Leguminosae-Faboideae, Gênero Adesmia DC. Boletim do Instituto de Biociências, Porto Alegre, n. 52, p. 1-157, 1993. 
MUNIZ, A. W.; BROSE, E. Isolamento e seleção de estirpes de rizóbio (Rhizobium leguminosarum bv. viceae) para lentilha em condições hidropônicas. Agropecuária Catarinense, Florianópolis, v. 21, n. 3, p. 91-94, 2008.

SCHEFFER-BASSO, S. M.; JACQUES, A. V. A.; DALL'AGNOL, M.; RIBOLDI, J.; CASTRO, S. M. J. Disponibilidade e valor nutritivo de forragem de leguminosas nativas (Adesmia DC.) e exóticas (Lotus L.). Revista Brasileira de Zootecnia, Viçosa, v. 30, n. 3, p. 975-982, 2001.
SCHEFFER-BASSO, S. M.; VENDRUSCOLO, M. C.; CECHETTI, D. Desempenho de leguminosas nativas (Adesmia) e exóticas (Lotus, Trifolium), em função do estádio fenológico no primeiro corte. Revista Brasileira de Zootecnia, Viçosa, v. 34, n. 6, p. 1871-1880, 2005.

TAIZ, L.; ZEIGER, E. Assimilação de nutrientes minerais. In: TAIZ, L.; ZEIGER, E. (Ed.). Fisiologia vegetal. 3 ed. Porto Alegre: Artmed, 2004. p. 285-308.

VINCENT, J. M. Manual practico de rhizobiologia. 1 ed. Buenos Aires: Hemisferio Sur, 1975. 200 p. 